11. Grossman W. Profiles in valvular heart disease. In: Grossman W, ed. Cardiac Catheterization, Angiography and Intervention. Philadelphia: Lea \& Febiger, 1991:557-581.

12. Wynne J, Green LH, Mann T, Levin D, Grossman W. Estimation of left ventricular volumes in man from biplane cineangiograms filmed in oblique projections. Am J Cardiol 1978;41:726-732.

13. D'Cruz IA, Aboulatta H, Killam H, Bradley A, Hand RC. Quantitative two-dimensional echocardiographic assessment of left ventricular shape in ischemic heart disease. J Clin Ultrasound 1989;17:569-572.

14. Lamas GA, Mitchell G, Flaker GC. The predictive value of LV systolic sphericity index, a magnification-independent assessment of LV shape (abstr). J Am Coll Cardiol 1996;27(suppl 1):223A.

15. Dodge HT. Implications of shape, stress and wall dynamics in clinical heart disease. In: Fishman AP, ed. Heart Failure. Washington, DC: Hemisphere Publishing Corporation, 1978:43-54.

16. Gould KL, Lipscomb K, Hamilton GW, Kennedy JW. Relation of left ventricular shape, function and wall stress in man. Am J Cardiol 1974;34:627-634.
17. Borow KM, Lang RM, Neumann A, Carroll JD, Rajfer SI. Physiologic mechanisms governing hemodynamic responses to positive inotropic therapy in patients with dilated cardiomyopathy. Circulation 1988;77:625-637.

18. Tishler PV, Niggel J, Borowski DT, LeWinter MM. Relation between left ventricular shape and exercise capacity in patients with left ventricular dysfunction. J Am Coll Cardiol 1993;22:751-757.

19. Kono T, Sabbah HN, Rosman H, Alam M, Jafri S, Goldstein S. Left ventricular shape is the primary determinant of functional mitral regurgitation in heart failure. J Am Coll Cardiol 1992;20:1594-1598.

20. St John Sutton M, Pfeffer MA, Moye L, Plappert T, Rouleau JL, Lamas G, Rouleau J, Parker JO, Arnold MO, Sussex B, Braunwald E, for the SAVE Investigators. Cardiovascular death and left ventricular remodeling two years after myocardial infarction: baseline predictors and impact of long-term use of captopril: information from the Survival And Ventricular Enlargement (SAVE) trial. Circulation 1997;96:3294-3299.

\title{
Prognostic Significance of Early Short-Term Measurements of Heart Rate Variability Following Acute Myocardial Infarction
}

\author{
Richard Steeds, MD, Janine Fletcher, PhD, Michael Smith, PhD, John West, MD, \\ Kevin Channer, MD, and John Townend, MD
}

This study of 164 subjects demonstrates that shortterm (5-minute) recordings of heart rate variability, performed within 48 hours of admission, identify those who survive acute myocardial infarction but have an adverse prognosis. (๑2004 by Excerpta Medica, Inc.

(Am J Cardiol 2004;94:1275-1278)

C ardiac autonomic control is profoundly deranged after acute myocardial infarction (AMI), with evidence of impaired vagal control and high levels of sympathetic activity. The extent of this derangement, in particular subnormal vagal activity, can be assessed by the measurement of baroreflex sensitivity and heart rate variability (HRV). There is considerable evidence to show that low levels of these markers of cardiac autonomic control are strongly and independently associated with an adverse prognosis. ${ }^{1}$ It is currently widely believed that abnormal cardiac autonomic control after AMI is not merely a consequence of the infarct but actively and deleteriously influences the clinical course of the disease. The predictive value of HRV has been exclusively derived from a 24-hour Holter electrocardiogram, which is slow and expensive to record and analyze. ${ }^{2}$ Isolated short-term (5minute) recordings may be of use, but data for their predictive value are scarce and have been derived

From the Department of Cardiovascular Medicine, Queen Elizabeth Hospital, Birmingham; the Department of Physiology, University of Birmingham, Birmingham; the Department of Medical Physics, Rotherham District General Hospital, Rotherham; and the Royal Hallamshire Hospital, Sheffield, United Kingdom. This study was supported by an unrestricted educational grant from Hoescht Marion Roussel, Uxbridge, Middlesex, United Kingdom. Dr. Steeds' address is: Queen Elizabeth Hospital, Edgbaston, Birmingham, B 15 2TH, United Kingdom.E-mail: rick.steeds@uhb.nhs.uk. Manuscript received March 10, 2004; revised manuscript received and accepted July 14, 2004. largely through the post hoc selection of suitable fragments of 24-hour recordings. ${ }^{3}$ The aim of this study was to determine the prognostic significance of shortterm recordings of HRV soon after AMI.

Subjects were recruited from among patients admitted to coronary care units at 3 hospitals in the United Kingdom between 1998 and 2000. This was a substudy of a double-blind, placebo-controlled comparison of the effect of early ( $\leq 48$ hours) and late (at 5 days) angiotensin-converting enzyme (ACE) inhibition with ramipril on short-term HRV. Data presented in this report are derived from HRV recordings taken before the study drug was administered. Patients were eligible if they presented $\leq 48$ hours of AMI in sinus rhythm. AMI was diagnosed according to criteria of the World Health Organization. ${ }^{4}$ Patients were excluded if they had established autonomic dysfunction, had a noncardiac disease likely to influence mortality rate, had a permanent pacemaker, were already treated with ACE inhibitors, or treatment with ACE inhibitors was contraindicated. Patients who were being treated with $\beta$-adrenoceptor antagonists before admission were eligible for inclusion provided that there was no change to drug dose after admission but before HRV was examined. No patients began taking $\beta$-adrenoceptor antagonists after admission but before HRV could be examined. All patients were discharged on an ACE inhibitor. All patients gave their written informed consent before entry into the ramipril study, which was approved by the local clinical research ethics committees. The substudy, which did not involve further patient contact, received separate approval.

Studies were performed $\leq 48$ hours of admission, with subjects in the semi-supine position after a 2-hour fast and $\geq 30$ minutes of rest in bed. Studies were performed on the admitting ward at the bedside. 
TABLE 1 Baseline Demographic Characteristics

\begin{tabular}{|lccl|}
\hline Variable & $\begin{array}{c}\text { Survivors } \\
(\mathrm{n}=143)\end{array}$ & $\begin{array}{c}\text { Deceased } \\
(\mathrm{n}=21)\end{array}$ & $\mathrm{p}$ Value \\
\hline Age (yrs) & $62 \pm 11$ & $69 \pm 11$ & 0.008 \\
Men & $103(72 \%)$ & $11(52 \%)$ & 0.08 \\
Smoker & $67(47 \%)$ & $10(48 \%)$ & 0.99 \\
Diabetes mellitus & $13(9 \%)$ & $0(0 \%)$ & 0.15 \\
Systemic hypertension & $43(30 \%)$ & $12(57 \%)$ & 0.01 \\
Total cholesterol $(\mathrm{mmol} / \mathrm{L})$ & $5.8 \pm 1.1$ & $5.8 \pm 1.3$ & 0.94 \\
Body mass index $\left(\mathrm{kg} / \mathrm{m}^{2}\right)$ & $27 \pm 4$ & $24 \pm 3$ & 0.02 \\
Positive family history & $37(28 \%)$ & $5(26 \%)$ & 0.99 \\
\hline \multicolumn{4}{|l}{ Values are mean $\pm \mathrm{SD}$ or numbers (percentages). } \\
\hline \multicolumn{4}{l}{} \\
\hline
\end{tabular}

Blood pressure was measured with automated oscillometric sphygmomanometers after this rest period. HRV was examined according to previously published methods. ${ }^{5}$ Subjects were studied during free respiration, and recordings of $\geq 256$ consecutive $R R$ intervals were made on each occasion. A respiratory signal was obtained, displayed, and recorded from 2 electrodes attached to the chest wall to monitor changes in impedance with respiration.

HRV analysis was performed according to previously published methods. ${ }^{5}$ Standard time-domain measures were calculated, including mean $\mathrm{NN}$ interval, SD of NN-interval values (an index that expresses overall variability), percent successive $\mathrm{NN}$-interval differences $>50 \mathrm{~ms}$, and root-mean-square of successive NN-interval differences. Percent successive NNinterval differences $>50 \mathrm{~ms}$ and root-mean-square of successive $\mathrm{NN}$-interval differences are measures of high-frequency ("beat-to-beat") variation mediated principally by the vagus nerve. ${ }^{6}$ Frequency-domain analysis was performed on stationary RR-interval series by using autoregressive modeling, as previously described. ${ }^{5}$ Stationarity of the time series was tested by calculation of the mean and variance of the first and last 128 beats of each recording period to verify a difference of $<10 \%$ in the values for each time series. The mean was subtracted from each point in the RR-interval series, and power spectral analysis was performed with Burg's algorithm. The power of each underlying frequency was quantified by decomposing the total variability signal with the method of Zetterburg, thus enabling determination of spectral powers at low frequency (centered at $\sim 0.1 \mathrm{~Hz}$ ) and at high frequency (corresponding to the observed respiratory frequency) expressed in absolute and normalized units ([power/total power $>0.04 \mathrm{~Hz}] \times 100 \%$ ).

All patients were flagged at entry through the National Health Service Central Registry, and notification was received of date and cause of death. Complete follow-up data were available for the cohort. Baseline demographic and clinical characteristics were compared with unpaired $t$ test and Fisher's exact test. Variables of markedly non-normal distribution (e.g., peak creatinine kinase) were appropriately transformed before analysis. The association of the selected HRV measurements and other variables with prognosis was assessed with univariate and multivariate Cox's regression analyses. Survival curves were

\begin{tabular}{|c|c|c|c|}
\hline & $\begin{array}{l}\text { Survivors } \\
(n=143)\end{array}$ & $\begin{array}{l}\text { Deceased } \\
(n=21)\end{array}$ & p Value \\
\hline Previous cardiac event & $26(18 \%)$ & $2(10 \%)$ & 0.33 \\
\hline Anterior wall AMI & 75 (51\%) & 7 (33\%) & 0.16 \\
\hline $\begin{array}{l}\log _{10} \text { (peak } \\
\text { creatine kinase) }\end{array}$ & $3.14 \pm 0.38$ & $3.20 \pm 0.37$ & 0.45 \\
\hline $\begin{array}{l}\text { Left ventricular } \\
\quad \text { ejection fraction (\%) }\end{array}$ & $52 \pm 14$ & $38 \pm 15$ & 0.001 \\
\hline Thrombolyzed & $125(87 \%)$ & 17 (81\%) & 0.49 \\
\hline
\end{tabular}

TABLE 3 Quartiles of Heart Rate Variability Analysis After Acute Myocardial Infarction

\begin{tabular}{|c|c|c|c|}
\hline & $\begin{array}{c}25 \% \\
\text { Centile }\end{array}$ & $\begin{array}{c}50 \\
\text { (median) }\end{array}$ & $\begin{array}{l}75 \% \\
\text { Centile }\end{array}$ \\
\hline Mean NN interval (ms) & 722 & 836 & 975 \\
\hline SDNN (ms) & 14.2 & 22.2 & 30.7 \\
\hline $\mathrm{rMMSD}(\mathrm{ms})$ & 8.3 & 16.0 & 25.9 \\
\hline pNN50 & 0.0 & 3.9 & 35.3 \\
\hline Low frequency $\left(\mathrm{ms}^{2}\right)$ & 13.9 & 42.7 & 142.3 \\
\hline Low frequency (nu \%) & 21.9 & 36.0 & 53.8 \\
\hline High Frequency $\left(\mathrm{ms}^{2}\right)$ & 21.2 & 69.3 & 219.8 \\
\hline High Frequency (nu \%) & 36.0 & 50.3 & 64.7 \\
\hline $\begin{array}{l}\text { Low frequency }\left(\mathrm{ms}^{2}\right) / \\
\text { high frequency }\left(\mathrm{ms}^{2}\right)\end{array}$ & 0.31 & 0.66 & 1.5 \\
\hline Total power $\left(\mathrm{ms}^{2}\right)$ & 203 & 491 & 875 \\
\hline \multicolumn{4}{|c|}{$\begin{array}{l}\mathrm{nu}=\text { normalized units; pNN50 = percent successive NN-interval differ } \\
\text { ences }>50 \mathrm{~ms} \text {; rMMSD = root-mean-square of successive NN-interval differ } \\
\text { ences; SDNN = SD of NN-interval values. }\end{array}$} \\
\hline
\end{tabular}

constructed by the Kaplan-Meier method. A 2-tailed p value $<0.05$ was considered statistically significant.

One hundred sixty-four subjects were recruited from among patients admitted to the coronary care units at 3 hospitals in the United Kingdom from 1998 to 2000. HRV analysis could not be performed in 27 patients after recruitment because of an excess ectopic count or poor-quality electrocardiographic data in the samples collected. Subjects in whom HRV analysis could not be performed were less likely to smoke (19 [70\%] vs 68 [50\%] nonsmokers, $p=0.05)$ and had higher peak levels of creatine kinase $(2,591 \pm 420 \mathrm{vs}$ $1,821 \pm 119 \mathrm{U} / \mathrm{L}, \mathrm{p}=0.02$ ), but there were no other differences from the group in whom HRV was analyzed. Over a median follow-up of 32 months (range 25 to 50), 21 subjects (13\%) died of cardiovascular disease, and 2 subjects were in the group whose HRV analysis could not be performed. Therefore, HRV data were available for 137 subjects, 19 of whom had died by the census date.

Baseline demographic characteristics are presented according to follow-up status in Table 1. Subjects who died were older, had a higher rate of hypertension, a lower body mass index, and lower left ventricular ejection fraction than did those who survived. Clinical characteristics of the index event are presented in Table 2. Most subjects presented with cardiac disease for the first time and received thrombolysis for acute infarction $(87 \%)$. Most of those recruited into the 
TABLE 4 Univariate Cox's Regression Analysis Comparing Survival Rate, Heart Rate Variability, and Baseline Variables.

\begin{tabular}{|lcc|}
\hline Variable & Relative Risk (95\% Cl) & $p$ Value \\
\hline Age (yrs) & $1.06 / \mathrm{yr}(1.01-1.010 / \mathrm{yr})$ & $0.008^{\dagger}$ \\
Women & $0.45(-0.19-1.06)$ & 0.07 \\
Body mass index $\left(\mathrm{kg} / \mathrm{m}^{2}\right)$ & $0.82 /$ unit $(0.69-0.98)$ & $0.03^{*}$ \\
Log 10 (peak creatine kinase) & $1.23(0.73-2.07)$ & 0.44 \\
Anterior wall AMl & $1.97(0.79-4.9)$ & 0.14 \\
Left ventricular ejection fraction $<35 \%$ & $9.9(3.4-28.4)$ & $<0.001^{\dagger}$ \\
Lowest quartile NN interval & $3.8(1.5-9.3)$ & $0.004^{\dagger}$ \\
Lowest quartile SDNN & $3.1(1.2-7.5)$ & $0.015^{*}$ \\
Lowest quartile rMSSD & $1.8(0.6-4.9)$ & 0.27 \\
Lowest quartile low frequency (nu) & $0.61(0.18-2.14)$ & 0.44 \\
Lowest quartile high frequency (nu) & $1.8(0.7-4.9)$ & 0.24 \\
Lowest quartile total power & $2.8(1.1-7.3)$ & $0.03^{*}$ \\
\hline${ }^{*} \mathrm{p}<0.05$. & & \\
${ }^{\mathrm{p}} \mathrm{p}<0.01$. & & \\
$95 \% \mathrm{Cl}=95 \%$ confidence interval; other abbreviations as in Table 3. & \\
\hline
\end{tabular}

HRV assessed by short-term recordings carry prognostic significance after AMI. Decreased HRV was associated with a threefold increase in risk of cardiac death on univariate analysis. The predictive value of HRV that had been assessed using short-term recordings was maintained despite performance of HRV assessment at an early stage after AMI.

Previous studies of the predictive value of short-term recordings of HRV have been largely restricted to retrospective analysis of clean periods extracted from longer 24-hour monitors. Malik and $\mathrm{Camm}^{7}$ compared the predictive value of 1-hour segments of 24-hour recordings with that of a complete 24-hour recording study received aspirin (155 subjects; 95\%) and all received ACE inhibitors (164 subjects; 100\%) before discharge from the hospital. Prognosis was not significantly associated with early or late commencement of ACE inhibition with ramipril $(p=0.28)$. Among the group as a whole, there was a low rate of prescription at discharge of statins (92 subjects; $56 \%$ ), $\beta$-adrenoceptor antagonists (56 subjects; 34\%), nitrates (10 subjects; 6\%), and calcium antagonists (13 subjects; $8 \%$ ). There was no difference between those subjects who survived and those who died in terms of the medication received at the time of discharge from the hospital after AMI. Information on changes in drug therapy after discharge was not available. Echocardiography was not performed routinely in this study, but data were collected from studies performed during the in-patient stay at the request of the clinician responsible for care. Assessment of left ventricular systolic function was made in only 99 subjects $(60 \%)$. There was no association between survival rate and performance/nonperformance of an echocardiogram $(\mathrm{p}=$ $0.53)$.

Measurements of assessed heart rate and HRV were divided into quartiles, and survival of those in the lowest quartile was compared with survival of those in the higher quartiles. The distribution of HRV analyses is presented in Table 3. The results of univariate Cox's regression analysis that compared survival rate, HRV, and baseline variables are presented in Table 4. Mean $\mathrm{NN}$ interval, SD of NN-interval values, and total power showed long-term prognostic significance soon after AMI. When assessed in multivariate models, mean NN interval continued to be of prognostic significance $(p$ $>0.05$ ). SD of $\mathrm{NN}$-interval values carried independent prognostic significance in the presence of all other variables with the exception of left ventricular ejection fraction. Total power was not included in the multivariate model because of the high correlation with SD of NNinterval values $(r=0.93)$.

This study provides evidence that decreases in timedomain (mean NN interval and SD of NN-interval values) and frequency-domain (total power) indexes of in 20 subjects who had serious cardiac events and 20 subjects who had no complication at 6 months. The 1-hour HRV recordings were capable of stratifying subjects according to increased risk, but the level of risk attributable changed according to the time of the hour taken for each patient. Bigger et $\mathrm{al}^{8}$ reported that spectral HRV from recording periods lasting from 2 to 15 minutes randomly selected from 24-hour Holter electrocardiograms predicted mortality rate after AMI. In these 2 studies, the predictive power of the shorter recordings was lower than that of the longer recordings. This finding was repeated by Fei et $\mathrm{al}^{3}$ who compared the predictive value of SD of NN-interval values taken from 5-minute segments with that of the HRV index taken from the same 24-hour recordings. Two other recent small studies have examined the prognostic utility of short-term HRV assessment after AMI. Vaage-Nilsen et $\mathrm{al}^{9}$ found that the SD of NNinterval values $<30 \mathrm{~ms}$ from a 5 -minute period of HRV assessment selected from a 48-hour Holter monitor recorded 1 week after AMI, age $>60$ years, and Holter evidence of ongoing myocardial ischemia were independent predictors of mortality rate in a group of 54 subjects followed for 9 years. In a study by Kautzner et $\mathrm{al}^{10}$ of 48 survivors of acute AMI, the SD of NN-interval values measured during a 30-minute recording 5 days after AMI was lower in 5 patients who died than in the remaining survivors at 1 year. Our findings are consistent with results from these studies in demonstrating the prognostic utility of short-term HRV assessment after AMI. The univariate relative risk identified in our study for low-quartile mean $\mathrm{NN}$ interval, SD of NN-interval values, and total power is of lower magnitude than that found by others who used full 24-hour recordings. ${ }^{1}$ Other studies that assessed short-term recordings are consistent in demonstrating a lower absolute level of risk compared with long-term recordings, although independent prognostic significance is maintained. ${ }^{3,7}$ Short-term recordings therefore remain adequate as a screening tool to identify high-risk subjects soon after infarction.

Short-term HRV assessment has several advantages over assessment based on 24-hour Holter elec- 
trocardiographic monitoring. First, practical advantages include the ability to study more patients over a shorter duration. This decreases the significant amount of complicated monitoring and analytic equipment required to provide 24-hour Holter recordings in all patients after AMI. Second, theoretical advantages exist in providing "cleaner" short-term assessment of HRV after AMI. HRV is mainly a reflection of the influence of the autonomic nervous system on the sinus node of the heart. Heart rate alters with many of the changes in demand on the cardiovascular system that are related to changes in respiration, posture, and physical or mental activity. These changes are induced by the control systems that coordinate the total pattern of activity in the patient. Ideally, some information should be available on this total pattern of activity before HRV can be interpreted appropriately. ${ }^{11}$ However, total activity is likely to be highly variable across patients studied over 24 hours at different times after AMI (24-hour monitors have been applied from discharge, from 5 days after admission, and $\leq 4$ weeks after discharge). ${ }^{1,2,8,12}$ Short-term recordings enable studies to be performed under more controlled, static conditions. This in turn should decrease the confounding effects of other activities on comparisons of intraand interindividual results. ${ }^{13-16}$

1. La Rovere MT, Bigger JT, Marcus FI, Mortara A, Schwartz PJ. Baroreflex sensitivity and heart rate variability in prediction of total cardiac mortality after myocardial infarction. Lancet 1998;351:478-484.

2. Kleiger RE, Miller JP, Bigger JT, Moss AJ. Decreased heart rate variability and its association with increased mortality after acute myocardial infarction. Am J Cardiol 1987;59:59:256-262
3. Fei L, Copie X, Malik M, Camm AJ. Short- and long-term assessment of heart rate variability for risk stratification after acute myocardial infarction. Am J Cardiol 1996;77:681-684.

4. WHO. Report of the Joint International Society and Federation of Cardiology/ World Health Organisation Task Force on standardisation of clinical nomenclature. Nomenclature and criteria for diagnosis of ischaemic heart disease. Circulation 1979;59:607-609.

5. Chowdhary S, Vaile JC, Fletcher J, Ross HF, Coote JH, Townend JN. Nitric oxide and cardiac autonomic control in humans. Hypertension 2000;36:264-269. 6. Task Force of the ESC and NASPE. HRV: standards of measurement, physiological interpretation, and clinical use. Eur Heart J 1996;17:354-381.

7. Malik M, Camm AJ. Significance of long term components of heart rate variability for the further prognosis after acute myocardial infarction. Cardiovasc Res 1990;24:793-803

8. Bigger JT, Fleiss JL, Rolnitzky LM, Steinman RC. The ability of several short-term measures of RR variability to predict mortality after myocardial infarction. Circulation 1993;88:927-934.

9. Vaage-Nilsen M, Rasmussen V, Jensen G, Simonsen L, Mortensen I. Recovery of autonomic nervous activity after myocardial infarction demonstrated by shortterm measurements of SDNN. Scand Cardiovasc J 2001;35:186-191.

10. Kautzner J, St'ovicek P, Anger Z, Savlikova J, Malik M. Utility of short-term heart rate variability for prediction of sudden cardiac death after acute myocardial infarction. Acta Univ Palacki Olomuc Fac Med 1998;141:69-73.

11. Karemaker JM. Heart rate variability: why do spectral analysis? Heart 1997;77:99-101.

12. Lanza GA, Guido V, Galeazzi M, Mustilli M, Natali R, Ieradi C, Milici C, Burzotta F, Pasceri V, Tomassini F, et al. Prognostic role of heart rate variability in patients with a recent acute myocardial infarction. Am J Cardiol 1998;82: 1323-1328.

13. Casolo GC, Stroder P, Signorini C, Calzolari F, Zucchini M, Balli E, Sulla A, Lazzerini S. Heart rate variability during the acute phase of myocardial infarction. Circulation 1992;85:2073-2079.

14. Singh N, Mironov D, Armstrong PW, Ross AM, Langer A. Heart rate variability assessment early after acute myocardial infarction. Circulation 1996; 93:1388-1395.

15. Lombardi F, Sandrone G, Spinnler MT, Torzillo D, Lavezzaro GC, Brusca A, Maliani A. Heart rate variability in the early hours of an acute myocardial infarction. Am J Cardiol 1996;77:1037-1044.

16. La Rovere MT, Pinna GD, Hohnloser SH, Marcus FI, Mortara A, Nohara R, Bigger JT, Camm AJ, Schwartz PJ. Baroreflex sensitivity and heart rate variability in the identification of patients at risk for life-threatening arrhythmias. Circulation 2001;103:2072-2077.

\title{
Echocardiographic Predictors of Prognosis After First Acute Myocardial Infarction
}

\author{
Omar Obeidat, MD, Mohsin Alam, MD, George W. Divine, PhD, Fareed Khaja, MD, \\ Sidney Goldstein, MD, and Hani Sabbah, PhD
}

\begin{abstract}
We prospectively studied 490 patients who had a first myocardial infarction and performed a complete 2-dimensional echocardiographic study $\leq 48$ hours of admission. In addition to left ventricular ejection fraction, multiple echocardiographic parameters of left ventricular systolic and diastolic performances were found to be independent predictors of 2-year mortality rate and congestive heart failure. (c)2004 by Excerpta Medica, Inc.
\end{abstract}

(Am J Cardiol 2004;94:1278-1280)

\footnotetext{
From the Henry Ford Heart and Vascular Institute, Detroit, Michigan. This study was supported by grant RO 1-HL49756-05 from the National Heart, Lung and Blood Institute, Bethesda, Maryland. Dr. Alam's address is: Henry Ford Hospital, Heart and Vascular Institute, 2799 West Grand Boulevard, K-14, Detroit, Michigan 48202. E-mail: malam1@hfhs.org. Manuscript received April 13, 2004; revised manuscript received and accepted July 27, 2004.
}

Depressed left ventricular (LV) ejection fraction (EF) is associated with poor prognosis after acute myocardial infarction (AMI), ${ }^{1,2}$ but hyperdynamic noninfarcted segments may confound LVEF measurement. Therefore, in the present study, we explored the prognostic value of multiple echocardiographic parameters of LV systolic and diastolic performances other than LVEF in patients who had a first AMI. These parameters are the LV wall motion score index (WMSI), diastolic and systolic sphericity indexes, deceleration time, and ischemic mitral regurgitation.

We prospectively studied 490 consecutive patients who had been admitted to our coronary care unit with first AMI from November 30, 1992 to December 17, 1996. AMI was diagnosed based on established electrocardiographic and enzymatic criteria and on clinical symptoms. Patients had to have ST-elevation AMI or 